\title{
Grisel Syndrome: Pathophysiological Evidence from Magnetic Resonance Imaging Findings
}

\author{
See-Hyun Park, MD, Sung-Hee Park, MD, Sang-Hee Lee, MD \\ Department of Physical Medicine and Rehabilitation, Institute for Medical Sciences, \\ Chonbuk National University Medical School, Chonbuk National University Hospital, Jeonju, Korea
}

Grisel syndrome is a condition of uncertain etiology characterized by a non-traumatic atlantoaxial subluxation following an infection in the head and neck region. Although first described in 1830, the exact pathophysiology of Grisel syndrome remains unclear. We present a case of atlantoaxial subluxation after acute lymphadenitis diagnosed with a dynamic computed tomography (CT) and magnetic resonance imaging (MRI). A previously healthy 9-year-old male patient presented with torticollis of sudden onset. Dynamic CT and MR imaging showed rotary atlantoaxial subluxation and inflammation surrounding the cervical spinal ligaments. A follow-up MRI of the cervical spine, taken 3 weeks after the onset of symptoms, showed a complete resolution of subluxation and inflammation surrounding the cervical spinal ligaments. In this case report, we support the hypothesis that an inflammation-induced laxity of the cervical ligaments is the pathologic key to Grisel syndrome using radiologic findings.

Keywords Lymhadenitis, Atlantoaxial joint, Torticollis

\section{INTRODUCTION}

Grisel syndrome is a condition of uncertain etiology characterized by a non-traumatic rotary atlantoaxial subluxation associated with a head and neck infection. Children are most frequently affected following an episode of infection in the head and neck region [1]. The presenting

Received November 9, 2011; Accepted September 27, 2012

Corresponding author: Sung-Hee Park

Department of Physical Medicine and Rehabilitation, Chonbuk National University Hospital, San 2-20, Keumam-dong, Dukjin-gu, Jeonju 561-180, Korea

Tel: +82-63-250-2299, Fax: +82-63-254-4145, E-mail: shpark0130@jbnu. ac.kr

(®) This is an open-access article distributed under the terms of the Creative Commons Attribution Non-Commercial License (http://creativecommons. org/licenses/by-nc/3.0) which permits unrestricted noncommercial use, distribution, and reproduction in any medium, provided the original work is properly cited.

Copyright ( $\odot 2013$ by Korean Academy of Rehabilitation Medicine symptom other than the history of an infection is a persisting torticollis with neck stiffness and/or pain upon neck movement.

There are different proposed explanations for the pathogenesis, and Grisel himself first suggested that the subluxation developed secondary to muscle spasm [2]. Watson-Jones and Roberts [3] suggested hyperemia of the blood supply of bone, following an infections or surgical trauma, leads to decalcification of the anterior arch of the atlas, and the decalcification, in turn, induces laxity of the anterior transverse ligament between the atlas and the axis. Wittek [4] further hypothesized that the subluxation is allowed by the distension of the ligaments with maintenance of the bony-ligamentous attachment. A two-hit hypothesis [5] proposed that non-traumatic subluxation requires pre-existing cervical ligamentous laxity, common among children, and inflammatory mediators carried to the cervical muscles by the pharyngovertebral 
plexus and these conditions induced cervical spasm and subsequent atlantoaxial subluxation.

We describe a case of Grisel syndrome in which sequential computed tomography (CT) and magnetic resonance imaging (MRI) scans were obtained. These imaging studies support the two-hit hypothesis of the etiology behind Grisel syndrome.

\section{CASE REPORT}

A 9-year-old male child was referred for evaluation of torticollis, and his recent medical history was significant for an episode of acute lymphadenitis on the neck 20 days ago, which was treated with intravenous antibiotics (ceftriaxone; Ceftriaxone, $2 \mathrm{~g}$ per day) and antiphlogistic
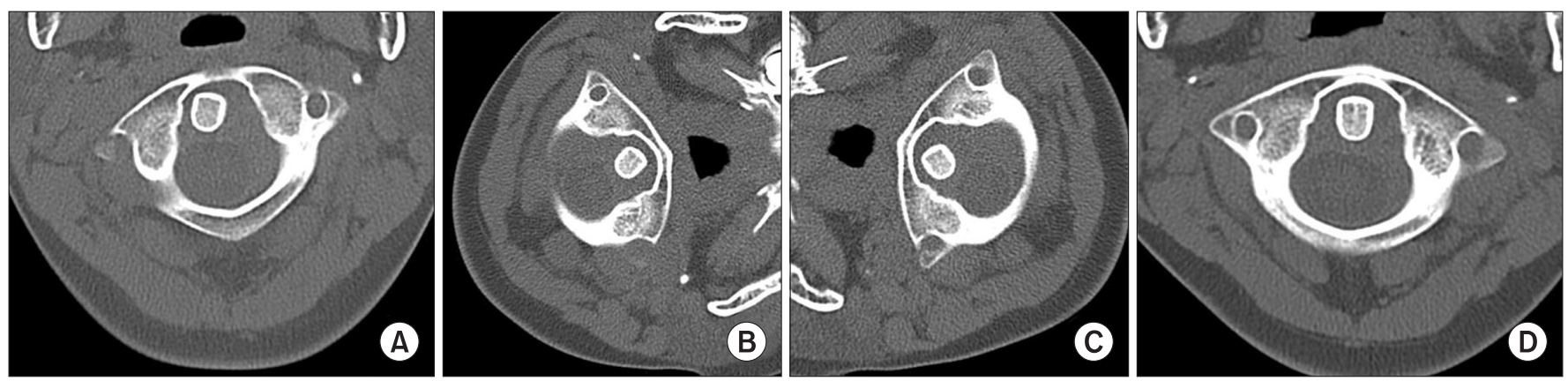

Fig. 1. (A) This dynamic computed tomography (CT) study demonstrates the rotary atlantoaxial subluxation with an anterior displacement of atlas relative to axis, corresponding to a Fielding type 2 subluxation. Rotation of the neck reveals asymmetric movement of the odontoid process. (B) Rotated to left side. (C) Rotated to right side. (D) The threeweek follow-up CT scan shows complete resolution of atlantoaxial subluxation.
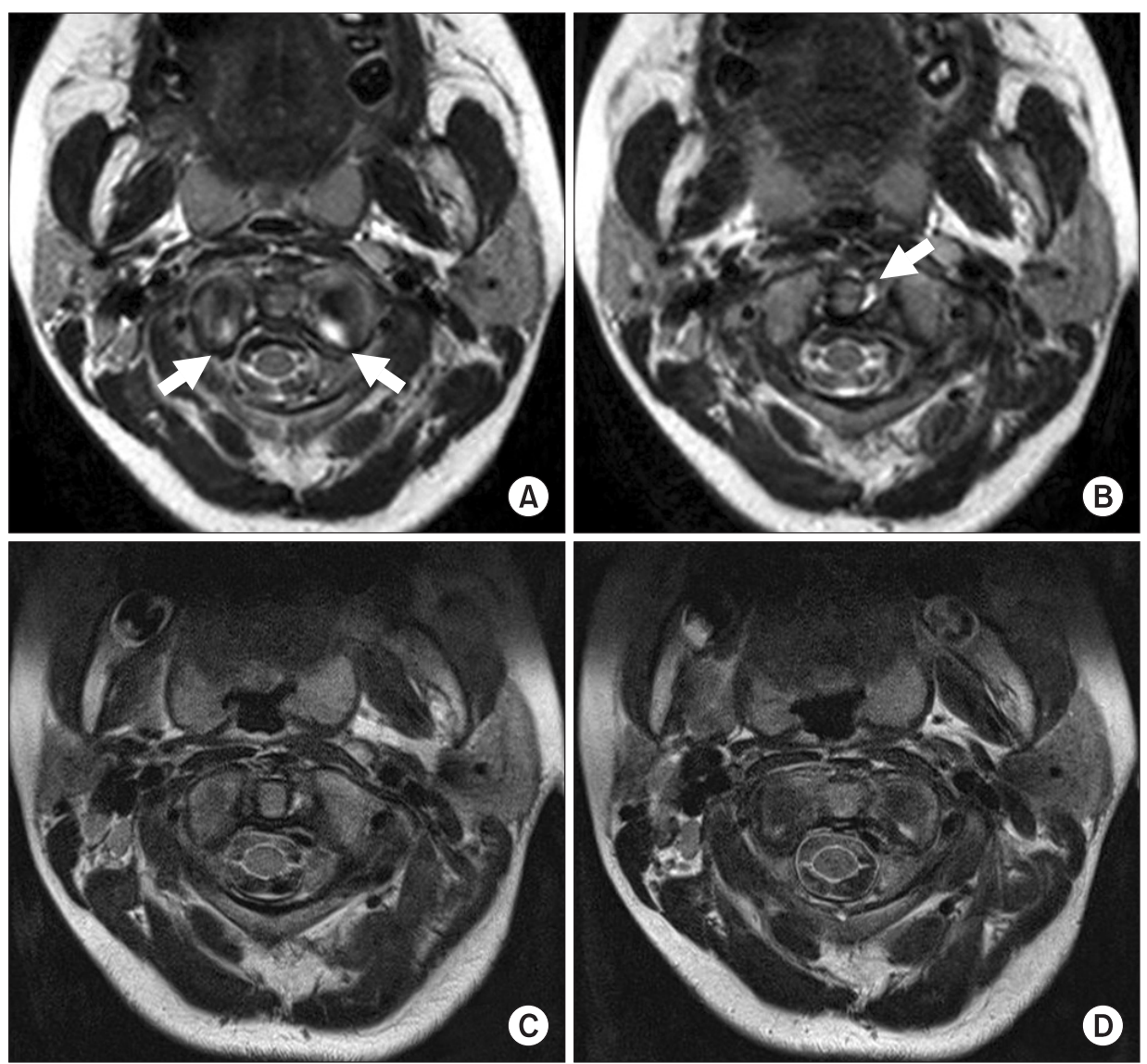

Fig. 2. The initial T2-weighted magnetic resonance imaging (MRI) study shows enhancement of atlantodental interval (A) and superior articular facet of axis (B). Repeated MRI, 16 days later, shows disappearance of signal change in atlanto-dental joint (C) and superior facet articulation of axis (D). 
therapy (diclofenac; Difexin, $45 \mathrm{mg}$ per day) for 9 days. Otherwise, the parents reported no history of trauma or pre-existing health condition. He presented with torticollis of sudden onset 20 days after acute lymphadenitis of the neck.

Physical examination revealed limited cervical range of motion. His head was rotated to the right and tilted to the left. Nuchal spasm was present on the left side. No neurological impairment was observed.

Contrast CT of the neck was performed with side-toside neck rotation, which revealed a significant rotary subluxation of $\mathrm{C} 1$ on $\mathrm{C} 2$ and an increased anterior atlantodental interval (Fig. 1), consistent with a Fielding type 2 rotatory subluxation. Contrast MRI of the neck revealed no neural involvement but demonstrated enhancement of the occipital condyle, $\mathrm{Cl}$ superior articular process, $\mathrm{C} 1 / \mathrm{C} 2$ facet joint and atlantoaxial interval, indicating inflammation of those structures (Figs. 2, 3). A Philadelphia neck brace was applied initially, and the patient was treated with halter traction for 14 days and antiphlogistic (morniflumate; Morniflu, $350 \mathrm{mg}$ per day) therapy for 7 days. The torticollis resolved after three weeks, and the patient had complete return of cervical ranges of motion. Follow-up with dynamic CT and MRI scans taken 21 days from onset of the torticollis revealed complete resolution of the inflammation. He was discharged home with the Philadelphia neck brace and had no lasting limitation or deficits.

\section{DISCUSSION}

Grisel syndrome primarily affects the pediatric population, with $68 \%$ of cases occurring in patients under the age of 12 years [6] and $90 \%$ under the age of 21 [7]. The syndrome has been reported to be associated with a head and neck surgical operation most commonly followed by upper respiratory infection as the second most common [7].

Patients with Grisel syndrome typically present with a fixed torticollis, possible history of fever, and other signs and symptoms of previous infection. On physical examination, nuchal muscle spasm is commonly observed. CT of the neck is the gold standard for diagnosis and further workup.

Several theories have been proposed to explain the pathogenesis of this inflammatory subluxation, but its etiology and exact pathogenesis continues to be debated. However, these hypotheses cannot account for the increased incidence of Grisel syndrome in children and a mechanism for the spread of infection or inflammatory mediators.

Battiata and Pazos [5] proposed the two-hit hypothesis that the first "hit" is a pre-existing cervical ligamentous laxity seen in the pediatric population at baseline. The normal adult atlas-dens interval ranges from 2.5 to $3 \mathrm{~mm}$, where as in children, this same interval ranges up to 4.5 $\mathrm{mm}$. This pre-existing laxity of the stabilizing soft tissues of $\mathrm{C} 1$ and $\mathrm{C} 2$ predisposes children for a potential subluxation event-the first "hit". The second "hit" is the cervical muscle spasm caused by the inflammatory mediators
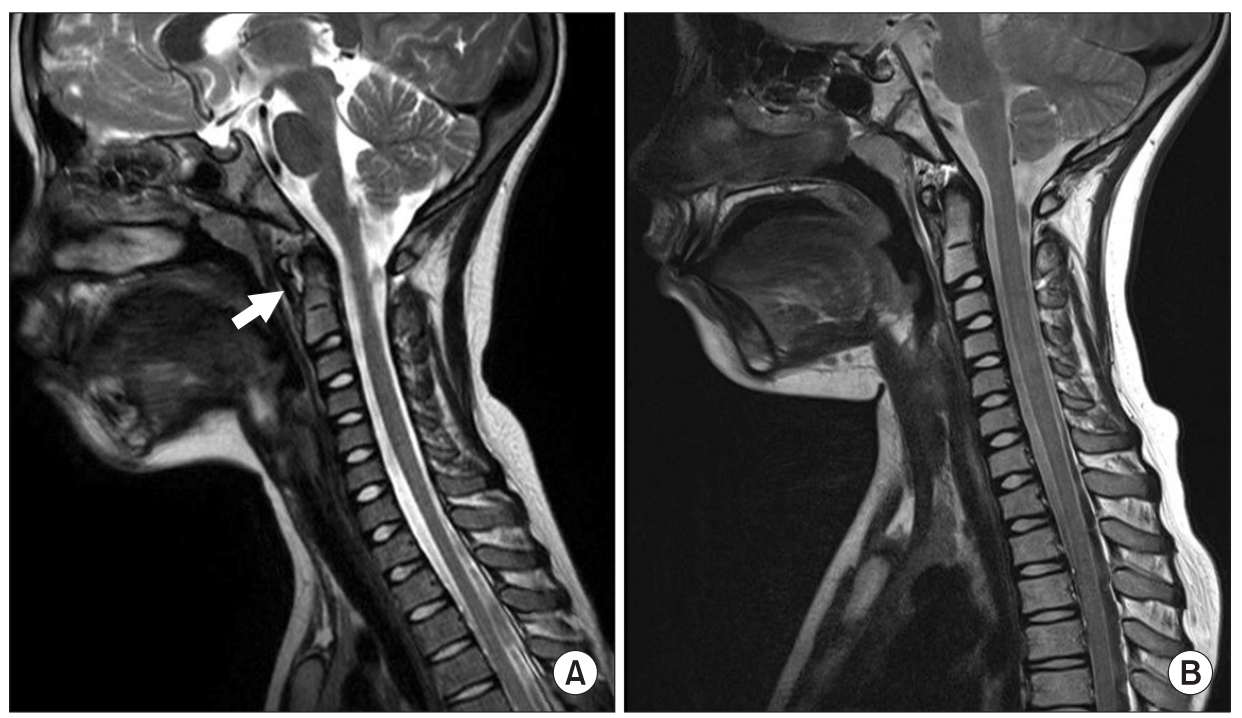

Fig. 3. (A) The initial sagittal T2weighted magnetic resonance imaging view shows enhancement of tissue surrounding the dens. (B) Repeat study shows resolution of the same. 
transported by the pharyngovertebral plexus.

A study by Parke et al. [8] provides an anatomic explanation for the second component of the two-hit hypothesis by demonstrating the role of pharyngovertebral veins play between the retropharyngeal space and atlantoaxial space. These veins drain the lymphatics of retropharyngeal space. In the presence of a head or neck infection, the pharyngovertebral veins would transport the inflammatory mediators from the pharynx to the soft tissues surrounding C1-C2 segment.

In a case report, Galer et al. [9] presented a 3-year-old girl with torticollis following an episode of tonsillitis and through a CT study, revealed low density fluid collection in the prevertebral space superior and posterior to the left palatine tonsil in addition to the C1-C2 atlantoaxial subluxation. In that study, the one-month follow-up CT scan revealed a normal alignment of the cervical vertebrae and resolution of the fluid collection.

Our case with MRI studies showed similar support for the inflammatory mediators being the cause of muscle spasm. Our case supports the hypothesis that inflammation-induced laxity of cervical ligament is the pathologic key to Grisel syndrome found in MRI findings. The enhancement of tissues surrounding cervical spine on the initial MRI and its resolution on the follow-up MRI study corresponded with the clinical presentation and resolution of torticollis in the patient.

Early detection of atlantoaxial subluxation and adequate antibiotics and antiphlogistic therapy can lead to early recovery. Deichmueller and Welkoborsky [10] reported that four of 12 patients who starting of therapy were delayed with Grisel syndrome had persisted torticollis despite adequate conservative treatment, and those patients required a delayed external fixation. Grisel syndrome should be taken into consideration for a pediatric patient who presents with acute torticollis after an episode of infection or head and neck surgery.

\section{CONFLICT OF INTEREST}

No potential conflict of interest relevant to this article was reported.

\section{ACKNOWLEDGMENTS}

This research was supported by Basic Science Research Program through the National Research Foundation of Korea (NRF) funded by the Ministry of Education, Science and Technology (NRF-2010-0005450).

\section{REFERENCES}

1. Sullivan AW. Subluxation of the atlanto-axial joint, sequel to inflammatory processes of the neck. J Pediatr 1949;35:451-64.

2. Wetzel FT, La Rocca H. Grisel's syndrome. Clin Orthop Relat Res 1989;240:141-52.

3. Watson-Jones R, Roberts PE. Calcification, decalcification, and ossification. Br J Surg 1934;21:461-99.

4. Wittek A. Ein fall von distensionluxation im atlantoepistropheal gelenke. Munch Med Wochenschr 1908;55:1936-9.

5. Battiata AP, Pazos G. Grisel's syndrome: the two-hit hypothesis-a case report and literature review. Ear Nose Throat J 2004;83:553-5.

6. Gourin CG, Kaper B, Abdu WA, Donegan JO. Nontraumatic atlanto-axial subluxation after retropharyngeal cellulitis: Grisel's syndrome. Am J Otolaryngol 2002;23:60-5.

7. Wilson BC, Jarvis BL, Haydon RC 3rd. Nontraumatic subluxation of the atlantoaxial joint: Grisel's syndrome. Ann Otol Rhinol Laryngol 1987;96:705-8.

8. Parke WW, Rothman RH, Brown MD. The pharyngovertebral veins: an anatomical rationale for Grisel's syndrome. J Bone Joint Surg Am 1984;66:568-74.

9. Galer C, Holbrook E, Treves J, Leopold D. Grisel's syndrome: a case report and review of the literature. Int J Pediatr Otorhinolaryngol 2005;69:1689-92.

10. Deichmueller CM, Welkoborsky HJ. Grisel's syndrome: a rare complication following "small" operations and infections in the ENT region. Eur Arch Otorhinolaryngol 2010;267:1467-73. 